\title{
What economic theory tells us about the impacts of reducing food losses and/or waste: implications for research, policy and practice
}

\author{
Martine M Rutten
}

\begin{abstract}
Background: Whereas the prevalence of hunger and food insecurity is often cited as a motivation for reducing losses and waste in agriculture and food systems, the impacts of such reduction on food security and the wider economy have not yet been investigated. This paper gives insights into these effects, the factors of influence, and derives implications for applied research, policy and practice.
\end{abstract}

Methods: We used economic theory to analyse the impacts of food loss reductions on the supply side and food waste reductions on the demand side. The analysis is graphical and uses intuitive low-dimension diagrams.

Results: The impacts of tackling food losses and waste differ from the size of food losses and waste and depend, in addition, on the extent to which they are avoidable, factors that cause them to arise (notably food prices) and the costs associated with measures to reduce them. Interactions within the food supply chain and the broader economy also affect the impacts. Trade-offs occur on the demand side where a reallocation of spending on previously wasted foods causes some producers to be worse off and some to be better off. Over time, producers tackling losses may have to incur welfare losses in the short run with gains in terms of increased revenues, if any, occurring later. Similarly, consumers may delay spending savings on previously wasted foods. As a consequence, the impacts, notably on food security and welfare, are ambiguous.

Conclusions: Further research should quantify the factors that play a role and carry out economy-wide impact analyses, employing a combination of macro, meso and micro-level tools, and presenting a comprehensive set of indicators that adequately capture broader societal impacts of tackling food losses and waste. This allows policy makers to better target policy and resources, identify complementary policies, and move beyond target-setting to addressing the underlying causes, whereby it is important to consider the whole food supply chain. Supply chain actors could contribute in terms of practical and innovative solutions where they matter most, and feed research and policy makers on the bottlenecks that explain why food losses and waste occur, and their relative importance.

Keywords: Economic theory, impacts, food losses, food waste, agriculture and food systems, food security

\section{Background}

Food waste is a contentious issue at times where hunger amongst the poor is still prevalent, and also vulnerable persons increasingly have to fear for food insecurity due to frequent food price peaks (for example, in 2007 to 2008 and 2011 to 2012) and adverse economic tidings. Given a growing population, pressures from competing

Correspondence: martine.rutten@wur.nl

International Policy Department, LEI Wageningen UR, Alexanderveld 5, 2502, The Hague, LS, Netherlands claims of feed, food and fuel demands on scarce natural resources of water and land, are only likely to increase.

The numbers suggest that globally, compared to 2009, $70 \%$ more food would have to be produced to satisfy the needs of a population growing by a third in 2050 [1]. Evidence from the Food and Agriculture Organization (FAO) also suggests that close to one third of the edible parts of food produced for human consumption is lost or wasted globally, equivalent to around 1.3 billion tons per year, and that the size of food losses and waste varies greatly by type of food, country or region and the stage

\section{Biomed Central}

(c) 2013 Rutten; licensee BioMed Central Ltd. This is an Open Access article distributed under the terms of the Creative Commons Attribution License (http://creativecommons.org/licenses/by/2.0), which permits unrestricted use, distribution, and reproduction in any medium, provided the original work is properly cited. 
in the food supply chain [2]. Specifically, worldwide food losses and waste per year are estimated at around 30\% for cereals, 40 to $50 \%$ for root crops, fruit and vegetables, $20 \%$ for oil seeds, meat and dairy and $30 \%$ for fish. Compared to other types of food, fruit, vegetables, roots and tubers suffer from relatively high losses and waste throughout the supply chain. Whereas losses and waste in industrialised and developing countries are roughly the same in terms of quantity (670 and 630 million tons respectively), in terms of value they are very different (US\$ 680 and US\$ 310 billion respectively), and also relative to the level produced in the market: for example, food losses and waste in Europe and North-America are around a third of production, whereas in sub-Saharan Africa and South and Southeast Asia this share is 25 to almost $40 \%$. Moreover, in low-income countries, these so-called losses in edible food mass destined for human consumption predominantly occur in agricultural production, post-harvest and processing stages (over $40 \%$ in the latter two stages). In medium- and high-income countries these losses (over 40\%) occur mostly at the end of the food chain (retail and final consumption), and are termed 'waste' [3]. The reference definition being developed by the FAO as part of the Save Food initiative [2] also includes qualitative losses such as losses in nutritional value. Reporting food losses and waste in terms of nutritional value leads to different numbers and percentages, though the patterns remain roughly the same [4].

These observations lead to the suggestion that reducing losses and waste in agricultural and food systems could relieve part of the pressures on scarce resources and enhance food security [5-8]. ${ }^{\mathrm{a}}$ However, the economic, social and environmental impacts of reducing food losses and food waste have, so far, not been investigated in detail empirically so it is unclear whether this is the case. ${ }^{\mathrm{b}}$ A reason for the lack of applied studies is the absence of reliable and consistent international data on food losses and food waste, the 2011 FAO study on Global Food Losses and Food Waste [2] being the first attempt to consistently present evidence on the extent of food losses and food waste throughout the supply chain from farm to fork, by broad commodity grouping, and for all regions in the world.

The lack of reliable and consistent macro data is fed by differences in definitions and methods of data collection between different countries. First, the distinction between food losses (operating on the supply side) and food waste (operating on the demand side) is not always that clear-cut. The definition of what is edible also varies across time and countries, and it depends on the perspective taken. For example, from a food security perspective, biofuels, feed or other non-food secondary uses of what was intended for human consumption may be considered a loss, whereas from the economic perspective of the generation of value added, they are not. Alternatively, from a health perspective, food intake may be more appropriate than food consumption and anything in excess of reference levels may be interpreted as waste. The latter is a rather extreme viewpoint (everyone who is overweight may then be seen as wasting food), but it illustrates that the definition used is crucial for the determination of the size of the problem. The project, Food Use for Social Innovation by Optimising Waste Prevention Strategies (FUSIONS) [9], which runs from 2012 to 2016, aims to address the harmonisation of food waste monitoring in the EU, which will help in clarifying the definitions and making available more consistent data on food waste for EU countries.

Given the lack of applied studies, the literature on impacts of (reducing) food losses and waste has been focusing on expressing food losses and waste in terms of the value of the resources (land, water) embodied in the output that could have been realised (production, consumption, nutrition), or the negative external effects that could have been avoided (emissions), by avoiding food losses and waste (see [10] for an overview). However, this only says something about the scale of the problem, not the actual impacts, as it ignores interactions between demand and supply, the role of the price mechanism therein, and more generally, interactions between actors and sectors in the agricultural sector, the food system and the wider (national and global) economy. Given the scale of the problem, these second-order effects could be quite considerable. For example, reducing food losses on the supply side (food waste on the demand side) could lower food prices quite considerably, leading to a change in demand (supply) of food so that the resulting impact is likely to differ from the value of resources or output embodied in the losses (waste) itself.

The predominantly qualitative literature $[2,4,11]$ reasons that food producers will profit from reducing food losses as this allows them to sell more at a lower cost so that their incomes increase. Consumers will benefit from reducing food waste as it saves them money which they can use elsewhere (on food or non-food products) and it lowers the price of the remaining food that is consumed in the market.

This paper aims to provide insights into the effects that are likely to occur if food losses and/or waste were to be reduced, to assert whether everyone is indeed better off than before, and what factors are crucial for determining the outcomes. After a brief discussion of the methodology, this paper will continue with a separate analysis of reducing food losses on the supply side and food waste on the demand side, which - as will become apparent - have distinctly different impacts, followed by a joint analysis of the influence of the types of supply 
and demand curves (elasticities) and other complicating factors that play a role in the outcomes. The paper then continues with a discussion in which a synthesis of the results is provided and implications for further applied research, policy and practice are derived. The final section concludes.

\section{Methods}

It is useful to start an analysis of the economy-wide impacts of reducing food losses and food waste with a theoretical framework, which guides the interpretation of the outcomes of a more complex, empirical model with added real-life complexities. This paper creates such a theoretical framework, which, to our knowledge, is missing from the literature so far. The paper provides a simple, intuitive, low-dimension diagrammatic analysis of expected impacts using standard economic theory of supply and demand and discusses what factors play a role. ${ }^{\mathrm{c}}$ It provides the groundwork for further applied analyses that are currently being undertaken in separate studies $[12,13]$ and may be undertaken in future.

\section{Results}

\section{Reducing food losses in supply}

In this section we examine the economic impacts of (reducing) food losses in a low-dimension partial equilibrium analysis. Figure 1 depicts the market for a food commodity, ${ }^{\mathrm{d}}$ with a standard upward sloping supply curve and a standard downward sloping demand curve. The price mechanism ensures that demand equals supply. The equilibrium is reached at point $\mathrm{A}$, where the price is $\mathrm{P}^{0}$ and the quantity traded is $\mathrm{Q}^{0}$. The depicted situation is best interpreted as capturing the full supply chain from farm to fork, but concealing the various intermediate stages in supply (for example, storage, transport, processing).

Let us assume that there are losses in the production and supply of this food commodity. In such a situation,

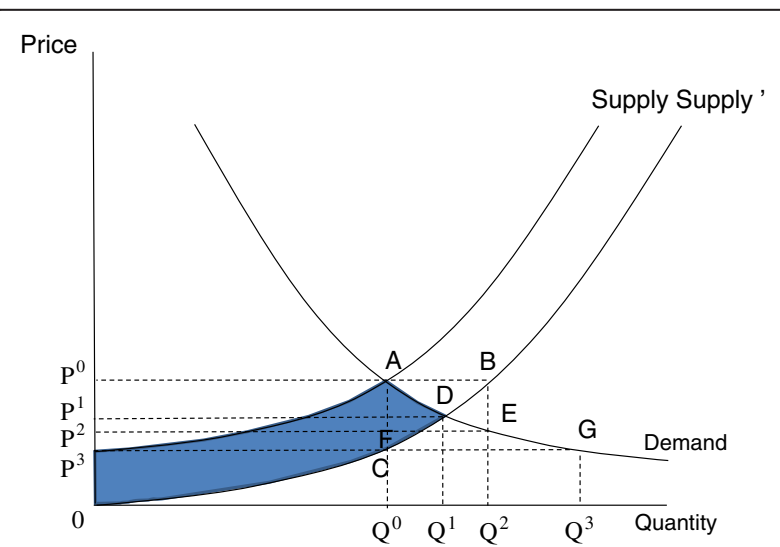

Figure 1 Impacts of reducing food losses in supply. Blue shaded area: overall welfare gain. the socially optimal supply curve, or the supply curve of this food commodity that would not have these losses, lies below the original supply curve, as depicted by Supply' in Figure 1; given the original price, $P^{0}$, more can actually be produced and supplied to the market $\left(Q^{2}\right.$ at point $B$ ), or the original quantity, $Q^{0}$, can actually be produced at a much lower cost $\left(P^{3}\right.$ at point $\left.C\right)$ if losses were to be absent. Note that the 'optimal' supply curve does not necessarily have to be parallel to the original supply curve, as the extent of losses may vary with the scale of production (and price). We abstract from this for ease of exposition.

\section{Impacts on price, quantity and welfare}

What happens if food losses in supply for the food commodity in question are tackled? Suppliers may, for example, be induced to tackle the losses because of the emergence of a new technology, which makes this possible and worthwhile, or new policies (regulations, taxes and subsidies) that penalise and stimulate reductions in food losses. The action of avoiding the losses, given the original demand curve and given the underlying motivation of doing so, would result in a lower price, $P^{1}$, and a higher equilibrium quantity, $Q^{1}$, in the market, as given by point $D$. At this new equilibrium consumers can buy more food at a lower price, resulting in a welfare gain to consumers as measured by the change in the consumer's surplus of $P^{0} A D P^{1}$. Similarly, producers can sell more, but at a lower price, resulting in a change in the producer surplus of $P^{1} D 0-P^{0} A P^{3}$, which is also positive. The overall welfare gain equals the sum of the change in the producer and the consumer surplus, which amounts to the area $P^{3} A D 0$, the blue shaded area between the new and old supply curve and under the demand curve.

These impacts - lower equilibrium price, higher quantity of food produced and consumed, and welfare gains for both producers and consumers - seem to be in line with the qualitative literature on impacts $[2,4,11]$ and are encouraging from the perspective of low-income countries, where food losses on the supply side dominate. From Figure 1, it can also be seen that the size of the impacts will depend, amongst others, on how big the losses are relative to the size of the market, which as shown, varies by type of food and country or region. Whatever the extent of the losses, in terms of quantity the size of the impact, $Q^{0} Q^{1}$, however, is much smaller than the original size of the problem, $Q^{0} Q^{2}$, which is due to the change in the price. This is in sharp contrast with how the current literature approaches impacts [10].

\section{Reducing food waste in demand}

In this section we examine the economic impacts of (reducing) food waste. Figure 2 depicts the market for a food 
commodity, again with the supply chain from farm to fork collapsed into a standard upward sloping supply curve and a standard downward sloping demand curve and the equilibrium at point $A$, where the price is $P^{0}$ and the quantity traded is $Q^{0}$.

Let us assume that there are losses in the consumption of this food commodity, in that consumers waste part of what they demand. In such a situation, the socially optimal demand curve, or the demand curve that would not have these losses, lies to the left of the original demand curve, as depicted by Demand' in Figure 2; given the original price, $P^{0}$, less needs to be consumed $\left(Q^{2}\right.$ at point $B)$ so as to reach a certain level of utility if waste was to be absent, or the original quantity, $Q^{0}$, represents a much lower value to the consumer $\left(P^{3}\right.$ at point $C$ ). Equivalent to the analysis on the supply side, the 'optimal' demand curve does not need to lie parallel to the original demand curve as the extent of waste in demand may vary with scale and price. We abstract from this for ease of exposition.

\section{Impacts on price, quantity and welfare}

What happens if food waste in demand for the food commodity in question is tackled? Consumers may, for example, be induced to tackle food waste because of a rising morale against waste, or new policies (regulations, taxes and policies) that penalise and stimulate reductions in food waste. Avoiding food waste in consumption, given the original supply curve and given the underlying motivation of doing so, would result in a lower price, $P^{1}$, and a lower equilibrium quantity, $Q^{1}$, in the market, as given by point $D$. Since producers are able to sell less and at a lower price, their welfare is negatively affected as shown by a change in the producer surplus of $P^{1} D E$ $P^{0} A E=-D A P^{O}$. Taking the difference between the area under the new and old demand curve and above the new and old price respectively, $P^{1} D F-P^{0} A G$, would result in a change in the consumer surplus of $P^{1} D B P^{0}$ $B A G F$, which here is negative. This would ignore, however, the fact the old demand curve encompasses waste, so that consumers only realise $P^{0} B F$ in value when consuming $Q^{0}$ of the food commodity at a price $P^{0}$; the remainder, $B A G F$, is lost due to wastage. The change in the consumer surplus if waste is avoided thus amounts to $P^{1} D F$ $P^{0} B F=P^{1} D P B^{0}$, which is now positive. The overall change in welfare that results equals $P^{1} D B P^{0}-P^{1} D A P^{0}=-B D A$, the red shaded area in Figure 2, which is negative. ${ }^{e}$

Whereas the equilibrium quantity goes down from $Q^{0}$ to $Q^{1}$, the distance $Q^{2} Q^{0}$, or $B A$, represented waste and was not eaten by consumers in the first place, so that actual food intake is going up from $Q^{2}$ to $Q^{1}$. Combined with the lower equilibrium price for food this is a

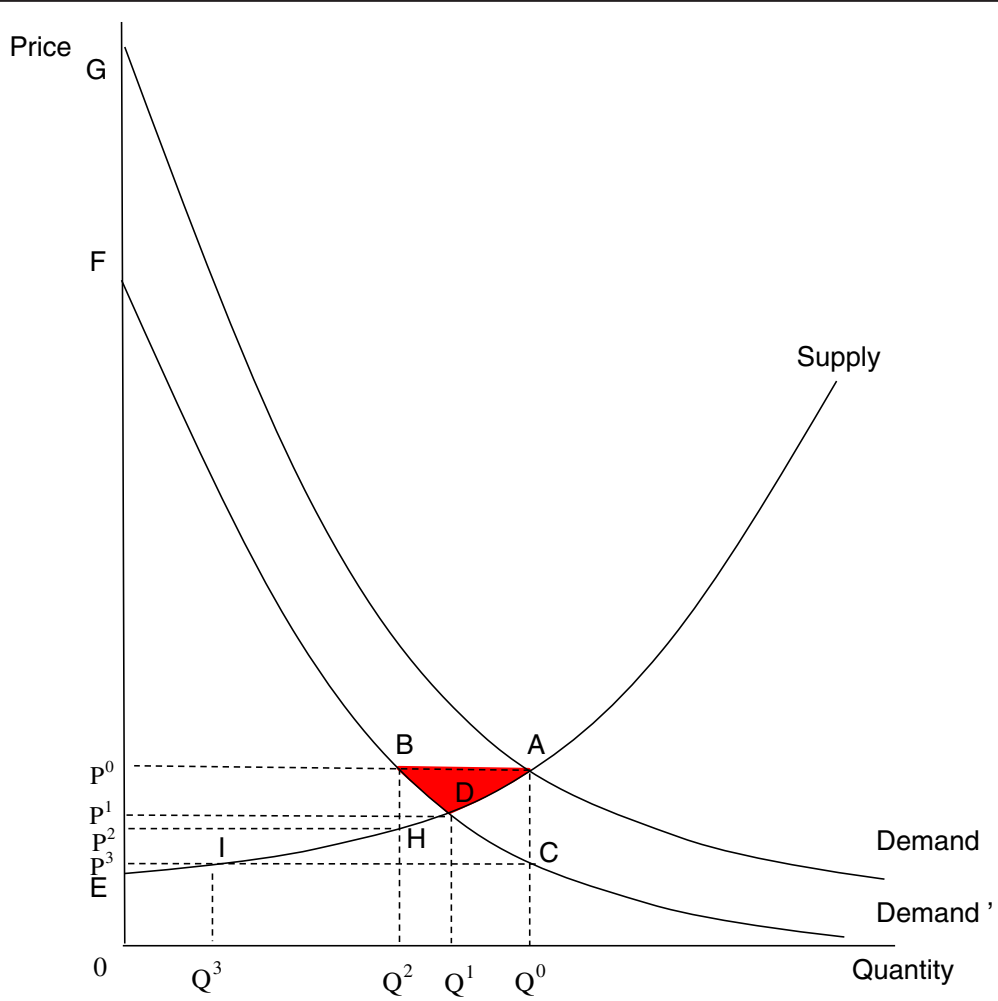

Figure 2 Impacts of reducing food waste in demand. Red shaded area: overall welfare loss. 
positive outcome for consumers in this market, whose food security is going up. This outcome is in line with statements made by the qualitative literature on impacts $[2,4,11]$ and is encouraging from the perspective of medium- and high-income countries, where food waste on the demand side is high on the policy agenda.

As before, the size of the impacts of reducing food waste in demand, in quantity terms $Q^{0} Q^{1}$, is influenced by the original size of the problem of food waste $\left(Q^{0} Q^{2}\right)$ (though much smaller compared to the original size). More importantly, what is concealed in the literature, is that trade-offs occur between producers and consumers in this market, with the former being worse off, and potentially leading to negative employment effects. Reducing food waste is simply not in the interest of producers who aim to maximise profits, even if it is on commodities that are wasted.

To conclude that the overall welfare impacts of reducing food waste in demand would be negative is wrong because the analysis is still not complete. The question that remains is what consumers would do with the saved expenses on this particular food commodity, $P^{0} Q^{0}$ $P^{1} Q^{1}$. Consumers may want to spend it now on the consumption of other commodities, and perhaps food. ${ }^{f}$ In this case it would lead to a shift in the demand curve(s) of the respective commodity(ies) in the opposite direction of that depicted in Figure 2, that is, a shift to the right, leading to a higher price and quantity in the accompanying market(s) and a welfare gain in this (these) market(s) for producers and consumers. The overall welfare change(s) in this (these) respective market(s) would be positive and equivalent to the difference between the new and old demand curves and above the supply curve (if one were to take the example of Figure 2, DAGF). If consumers add the saved expenditures on previously wasted food to savings, the money could be used for consumption in future with associated utility gains then being realised.

The overall welfare impacts in the market of the food commodity in which waste is reduced and other markets combined thus depends on consumer preferences. Nonetheless, the welfare loss for producers, which occurs due to waste reduction by consumers of the food commodity in question and results in a fall in sales and price, is highly likely to be compensated for by welfare gains for producers and consumers in other markets benefiting from increased spending, whether or not over time, because waste is avoided and resources that were previously spent on it are now put to a productive and welfare-generating use.

\section{Varying the slope of demand and supply curves: inter- temporal effects}

The outcomes, and thus, the size of the welfare effects, depend on the slope of the demand and supply curves.
Assuming that the extent of food losses, respectively waste, is the same as before (that is, the shift in the supply or demand curve is of the same distance as before), and independent of scale and/or price, we can distinguish the following cases, discussed separately for the case of reducing food losses in supply and reducing food waste in demand.

\section{Impacts on the outcomes of reducing food losses in supply}

In the presence of a perfectly inelastic (that is, vertical) demand curve, the new equilibrium is at point $C$ (same quantity, lower price), with consumers receiving all the gains from reducing food losses in the form of a lower price and a welfare gain of $P^{0} A C P^{3}$. In the presence of a perfectly elastic (that is, horizontal) demand curve, avoiding food losses in supply results in a new equilibrium at point $B$, where all the gains translate into an increase in the equilibrium quantity supplied and demanded (and no change in price). This results in a welfare gain to producers of $P^{3} A B 0$.

Varying the slope of the demand curve thus influences the distribution of welfare gains over producers and consumers, but as shown, does in itself not lead to sign changes. With the demand for food generally being fairly inelastic, though not perfectly, the truth is likely to lie in between the two extreme cases presented. ${ }^{\mathrm{h}}$

Similarly, if supply is perfectly inelastic (vertical supply curve), the equilibrium is at point $E$, resulting in a lower equilibrium price and higher equilibrium quantity compared to the analysis before. Consumers gain by $P^{0} A E P^{2}$, but producers here lose out by $F E Q^{2} Q^{0}-P^{0} A F P^{2}$. The overall welfare result, however, is positive (area $A E Q^{2} Q^{0}$ ). Finally, a completely elastic (horizontal) supply curve results in an equilibrium at point $G$, whereby demand increases the most (to $Q^{3}$ ) as the price falls the most (to $P^{3}$ ) and all welfare gains end up with the consumers who benefit to the maximum extent possible, by area $P^{0} A G P^{3}$.

A vertical supply curve is representative of the short run, where it is generally difficult for producers of food to respond to price changes, whereas a horizontal supply curve corresponds to a long-run situation, where producers of agri-food commodities can respond and generally are price takers in a highly competitive market. The actual representation is likely to lie somewhere in between, but in the short run will be closer to being inelastic and in the long run will be more elastic. ${ }^{i}$ These findings thus suggest the importance of inter-temporal effects, which are typically ignored in the literature. Specifically, overall welfare and the welfare of consumers generally goes up, whereas that of producers could go down, namely in the case of supply being relatively inelastic, that is, in the short run: the increase in sales from selling previously lost produce could be insufficient to compensate for the price decrease on existing sales. 
In the long run, supply of agricultural commodities is more elastic, so then welfare gains are likely to occur and most of these end up with the consumer.

\section{Impacts on the outcomes of reducing food waste in demand}

Here we ignore what happens in other markets and focus on the market of the food commodity in which waste in demand is reduced (see Figure 2). Specifically, in the presence of a perfectly inelastic (that is, vertical) demand curve, the new equilibrium is at point $H$, resulting in a lower equilibrium quantity, $Q^{2}$, and a lower price, $P^{2}$. The change in the consumer surplus would again be positive and equal to the area, $P^{2} H B P^{0}$, whereas the change in the producer surplus would be negative and equal to $-P^{2} H A P^{0}$. The resulting overall welfare loss in this market is - $H A B$, slightly more negative than before. In the presence of a perfectly elastic (that is, horizontal) demand curve, avoiding food waste in demand results in a new equilibrium at point $I$, with an even lower quantity, $Q^{3}$, and price, $P^{3}$. This would result in a higher welfare loss in this market for producers, equal to $-P^{3} I A P^{0}$, but no impact on consumers. Similarly, if supply is perfectly inelastic (vertical supply curve), the equilibrium is at point $C$, where the reduction in wastage in demand fully translates into a lower equilibrium price, $P^{3}$, but has no impact on quantity. The lower equilibrium price benefits consumers by $P^{3} C B P^{0}$, but hurts producers, who suffer a maximum loss of $-P^{3} C A P^{0}$, resulting in an overall welfare loss in this market of - $C A B$. Finally, a completely elastic (horizontal) supply curve results in an equilibrium at point $B$, whereby there is only a negative impact on the equilibrium quantity, to $Q^{2}$, but no impact on price, which would result in zero impact on producers and consumers in this market.

In this simple, low-dimension diagrammatic analysis of reducing waste in demand, consumer welfare generally goes up or at best remains the same, whereas producer welfare falls or at best remains the same, resulting in an overall welfare impact ranging from negative to, at best, zero in the long term if the supply of agri-food commodities would be almost perfectly elastic. As indicated before, welfare gains to producers and consumers in other markets will result if consumers decide to spend the saved expenditures on other commodities. In sum, with elasticities differing for different commodities and in the short and long run, the truth about what will happen in reality when reducing food waste will lie somewhere in between, with trade-offs occurring between consumers who benefit, and producers of the food commodity for which waste is reduced, who lose out to the benefit of other producers who gain from increased spending now or in future.

\section{Complicating factors}

We have made various simplifying assumptions to come to our findings. Below we discuss how these complicating factors may alter the results.

\section{The extent to which food losses and/or waste are avoidable}

The impacts may be much smaller if only a part of the food losses and/or waste is avoidable. Unavoidable food losses, respectively waste, are generally considered by the literature as being inedible, such as bones, skins and peelings and represent about 19\% of the food lost and wasted [14]. The remainder could possibly be avoided. The FAO uses conversion factors of the same order of magnitude to determine which part of the agricultural product is edible, specifically in the range of 0.7 to 1 , with the exception of fish, which has a conversion factor of 0.5 [2].

\section{Costs of reducing food losses and/or waste}

What can feasibly or cost-effectively be avoided depends not only on the benefits but also on the costs involved in reducing food losses and/or waste compared to the status quo. If there are costs involved in reducing food losses, these will have a price-increasing and quantityreducing effect in the market for the food commodity in question, counteracting the original shift down (or to the right) that occurs when reducing food losses in supply and counteracting the observed welfare gains. The literature remains surprisingly silent on the issue of costs of reducing food losses and waste (see [4] for some anecdotal evidence), which leads to incomplete and unfounded statements on impacts. Whereas some measures to reduce food losses on the supply side, such as improved harvesting techniques by farmers or other behavioural changes (also by other actors in the supply chain), may cost relatively little, other measures, such as investments in storage facilities and improved transport (including cold chain), may cost much more. Consistent data on costs of measures to tackle food losses are hard to find, not the least because they are likely to vary with the food commodity in question, the segment of the food supply chain, and by country due to differences in, for example, the level of development, location and climatic conditions.

Similarly, the net welfare gains may be lower if there are costs involved with reducing food waste by the consumer, which counteract the original shift down (or left) that occurs when reducing food waste in demand. All in all, although behavioural change on the part of consumers to waste less food may directly cost relatively little, it may require consumers, for example, to go more often to the supermarket to buy fresh food that is better adjusted to their needs and wants, which involves time 
and effort. In other words the perceived or indirect cost by the consumer may still be high.

\section{Factors causing food losses and/or waste}

Food losses may themselves be explained by underlying factors, including scale of production and price. Relatively low food prices are said to be an important cause of food losses in supply and food waste in demand $[2,4,10]$. If we assume that food losses decrease with greater scale (and price), the observed impacts of reducing food losses will be greater if the market is small and the price is low. This can be depicted by supply curves with and without losses, which are increasingly converging to one another as the quantity and price increases.

If we were to assume that food waste is increasing with the amount consumed and decreasing with the price paid for food, reducing food waste results in greater impacts if the market is of reasonable size (that is, the quantity traded is high and the price is low). This can be depicted by increasingly diverging demand curves with and without waste as the quantity increases and the price decreases.

Combining aforementioned observations, thus, it may well be that from the perspective of costs and benefits it is better for agri-food producers and suppliers to allow for some food losses (at a relatively low cost) rather than to take measures (at a relatively high cost and low returns) to combat them (also suggested by [4]). Similarly, for consumers the relatively low cost (price) of food may prevent her from taking action.

\section{Interactions within the supply chain}

Another simplification is that the framework presented cannot address where the losses occur in the supply chain (primary agricultural production stage, processing stage, storage and transport stages), which is shown to vary quite a bit, as do causes and measures to tackle the losses $[2,4]$. As a consequence, costs to tackle food losses may be borne in, say the beginning, of the supply chain, whereas the benefits may occur later in the chain. This and the time dimension associated with costs occurring upfront, and benefits - if any- occurring later, often impedes relevant actors to take action. Anecdotal evidence comes from farmers improving the quality of their crop or improving storage that reduces food losses, which subsequently cannot be sold since they do not have market access or as the market cannot absorb the additional quantity, or, if it can be sold it is sold to traders at a price that does not recuperate the original investment made. Another example is that of food processors making technical improvements that are negated by retailers when they withdraw food orders that were originally agreed upon. Finally, farmers are often not able to sell crops that do not meet marketing standards (for example, on shape) but are otherwise perfectly fine for human consumption, as they are not accepted by retailers and consumers $[2,4,15]$.

\section{Interactions with other markets and actors}

Our analysis makes the usual ceteris paribus assumption, that is, that all else remains the same, which is highly unlikely. For example, reducing losses generally results in a lower price, which could increase demand elsewhere in the system, potentially leading to second-order effects. An example is food as feed (for example, from grains or vegetables and fruits) becoming cheaper if losses in production and supply fall, as a result of which meat demand may go up (as meat will become cheaper to produce due to lower intermediate input costs of using feed), which is less efficient in the use of resources compared to crops in that it uses relatively more water and land $[16,17]$. Similarly, biofuel use may go up. Another example is that households may waste more if food becomes cheaper, undoing the positive impact of reducing food losses on the supply side. Of course, consumers under pressure from prevailing morale may also display the opposite behaviour and reduce food waste. Opening up the framework for trade, it is likely that the increased net food supply at a lower price will find its way to export markets and is able to better compete with imports, thus improving the trade balance for the food commodity in question. This does not alter the main outcomes.

\section{Discussion}

\section{A synthesis of the results}

Table 1 integrally presents the results of the supply and the demand side analyses of tackling food losses and waste respectively. It summarises what happens to the market equilibrium (price, quantity; second and third column) and consumer and producer welfare (fourth and fifth column, and sixth column for the overall effect) in the market for the food commodity in question and for varying assumptions regarding demand and supply curves, providing the boundaries for what may happen (by row). The last column considers the impact of other factors that are of influence, where possible, relaxing some of the simplifying assumptions made throughout the analyses.

What has become evident from economic theory is that the impacts of tackling food losses in supply and food waste in demand in terms of quantity are different from the original size of the food losses and waste, and depend crucially on the extent of the food losses and/or waste relative to the size of the market, the extent to which they are avoidable, factors that cause them to arise in the first place (notably the level of food prices), the costs associated with measures to reduce them and interactions within the food supply chain and with other 
Table 1 Summary of impacts of reducing losses and waste in the market for a food commodity

\begin{tabular}{|c|c|c|c|c|c|c|}
\hline \multirow[b]{2}{*}{ Reducing losses in supply } & \multicolumn{2}{|c|}{$\begin{array}{l}\text { Impact on market } \\
\text { equilibrium }\end{array}$} & \multicolumn{3}{|c|}{$\begin{array}{l}\text { Welfare impacts in the commodity } \\
\text { market }\end{array}$} & \multirow{2}{*}{$\begin{array}{l}\text { Factors of influence and impacts } \\
\text { Extent of food losses relative to the size } \\
\text { of the market }\end{array}$} \\
\hline & Price & Quantity & Consumers & Producers & Total & \\
\hline Perfectly inelastic demand curve & - & Constant & + & Constant & + & $\begin{array}{l}\text { If losses increase (decrease) with scale } \\
\text { and price, then impacts are larger at } \\
\text { higher (lower) scale and price }\end{array}$ \\
\hline Perfectly elastic demand curve & Constant & + & Constant & + & + & $\begin{array}{l}\text { Impacts may be smaller if not all losses } \\
\text { are avoidable }\end{array}$ \\
\hline Perfectly inelastic supply curve & - & + & + & $?$ (- in example) & + & $\begin{array}{l}\text { If loss reductions involve costs then welfare } \\
\text { impacts will be lower. This has a price } \\
\text { increasing and quantity reducing effect. }\end{array}$ \\
\hline Perfectly elastic supply curve & - & + & + & Constant & + & $\begin{array}{l}\text { Interactions within the supply chain and } \\
\text { with other actors and/or markets? }\end{array}$ \\
\hline Reducing waste in demand & Price & Quantity & Consumers & Producers & Total & $\begin{array}{l}\text { Extent of food waste relative to the size } \\
\text { of the market }\end{array}$ \\
\hline Perfectly inelastic demand curve & - & - & + & - & - & $\begin{array}{l}\text { If waste increases (decreases) with scale } \\
\text { and decreases (increases) with price, then } \\
\text { impacts are larger at higher (lower) scale } \\
\text { and lower (higher) price }\end{array}$ \\
\hline Perfectly elastic demand curve & - & - & Constant & - & - & $\begin{array}{l}\text { Impacts may be smaller if not all waste } \\
\text { is avoidable }\end{array}$ \\
\hline Perfectly inelastic supply curve & - & Constant & + & - & - & $\begin{array}{l}\text { If waste reductions involve costs then } \\
\text { welfare impacts will be lower. This has a } \\
\text { price increasing and quantity reducing } \\
\text { effect. }\end{array}$ \\
\hline \multirow[t]{2}{*}{ Perfectly elastic supply curve } & Constant & - & Constant & Constant & Constant & $\begin{array}{l}\text { Consumer preferences: if consumers spend } \\
\text { savings from reducing waste: positive impact } \\
\text { on price, quantity and welfare of producers } \\
\text { and consumers in other commodity markets }\end{array}$ \\
\hline & & & & & & $\begin{array}{l}\text { Interactions within the supply chain and with } \\
\text { other actors and/or markets? }\end{array}$ \\
\hline
\end{tabular}

+ , positive impact; -, negative impact; Constant, implies that there has been no impact. Whereas the direction of effects is shown, their magnitudes are not, as they depend on the underlying shocks and how they impact upon each of the variables.

actors and markets. Impacts also vary with the slope of the demand and supply curves and consumer preferences play an important role on the demand side. If one takes all these factors into account, one cannot be certain a priori what the impacts will be, notably when it comes to food security and welfare. Trade-offs are shown to occur with winners and losers, most visibly on the demand side where a reallocation of spending away from previously wasted food towards other products or commodities (and perhaps food) causes some producers to be worse off and some to be better off. Trade-offs also arise over time, as in the short run, producers may have to incur costs and/or welfare losses when food losses are tackled with gains in terms of increased revenues, if any, occurring later, and consumers may delay spending savings on previously wasted foods due to market uncertainty and increased costs of living.

The analysis becomes much more complicated if food waste in demand and food losses in supply would change simultaneously, possibly in reaction to one another, and on a global scale. What exactly will happen remains an empirical question and is best investigated in further applied research. The following subsections discuss the implications for further research on the economy-wide impacts of reducing food losses and/or waste, the implications for policy and in practice.

\section{Implications for research}

The theoretical analysis provides a useful construct to shape the research agenda on the economy-wide impacts of reducing food losses and/or waste. This section aims to draw the contours of such a research agenda and what this would add to current literature, looking at it from the perspective of economic science. It provides a starting point for further applied and policy-relevant analyses, and is unlikely to be complete, because as analyses get underway, new insights will emerge that will and should influence the research agenda further.

The first and foremost implication for research is to quantify the factors that play a role. Most importantly, this includes improving data on food losses and waste and the extent to which this is avoidable throughout the 
supply chain for detailed agri-food commodities and by country, using commonly agreed definitions. At the country level and at the international level (for example by FAO, Organization for Economic Cooperation and Development (OECD), Eurostat and FUSIONS) a lot of effort is currently going into improving the data $[9,18]$. It also includes quantifying the factors causing food losses and food waste. This may, for example, result in food loss and food waste being analysed as a decreasing function of food prices. This has, to our knowledge, not been done yet. Finally, it includes estimating the cost of tackling food losses and food waste (depends on measures taken). Preliminary work is being undertaken to come to cost ranges for policy measures to address food losses and waste [19], but more work is needed to come to more precise estimates of the cost to the various actors in the supply chain, beyond that presented on an anecdotal basis [4].

Second, with this information one could investigate the impacts of reducing food losses and/or waste using applied empirical models. Although the main interest here is in the economy-wide or macro-level impacts, it is useful to combine or complement this with meso- and micro-level analyses to get more detailed impacts for the various actors in the food supply chain from farm to fork. Methodologies that are suitable for each of these levels of analysis are discussed below.

At a macro level, it seems appropriate to use computable general equilibrium (CGE) models that are firmly grounded in microeconomic theory, capturing demand and supply responses to changes in relative prices, and are able to address interactions within the food supply chain and the wider economy that are shown to be important. Applications of impact analyses are underway regarding the issue of reducing food losses in supply in the Middle East and North Africa [12] and regarding the issue of reducing food waste in demand compared with a movement towards healthier diets in the EU [13] using a global CGE model. Due to its global reach, the latter study can also address the question of how reducing food waste in industrialised countries (the EU) affects food security in poor countries (sub-Saharan Africa). Specifically, if the former reduce food waste this may increase food availability on the world market, which lowers world food prices and could benefit net food consumers (or importers) but harm net food producers (or exporters) in the developing world. These impacts will depend on trade patterns, which are influenced by whether or not tariff or non-tariff barriers to trade exist, which may prevent the free movement of food commodities altogether. In order to obtain more disaggregated impacts, a partial equilibrium (PE) model that has more detail in agri-food production and trade may be used. To our knowledge, there are no PE studies on the impacts of (reducing) food losses and waste, although the OECD has an interest in going in this direction using the AGLINK- COSIMO model framework [20]. As a PE model cannot capture economy-wide linkages, a combination of CGE and PE modelling may be most appropriate, but will be computationally more demanding. Macroeconomic CGE- or PE-type models are being increasingly coupled with models that can address noneconomic impacts, such as environmental impacts (biodiversity and emissions, for example [21]) and health impacts (number of deaths avoided, health cost savings, for example [22]). These are useful directions for further work as food waste and more broadly food consumption patterns and the motivations to adjust these are strongly related to environmental and health concerns, which a pure economic focus would fail to address.

At a meso level, cost-benefit analyses along the value chain could add insights into where food losses and waste occur in the chain, why they occur, what the consequences are, and what the costs and benefits are of tackling losses, taking into account that the various segments of the food supply chain interact. Such analyses, to our knowledge, have not been carried out as yet.

At a micro level, further analyses could shed light on consequences of tackling food losses and waste for one segment of the food supply chain, for example households. Poverty impacts for different types of household can be obtained using a coupling of macro models with micro-simulation models (for example [23]), by imposing a top-down household decomposition (for example [24]) or using a fully integrated micro-macro model (for example [25]). At the household level it is important that consumer behaviour regarding food waste is appropriately captured. This is strongly related to consumer preferences regarding food and more broadly, dietary change. Although there is much literature on how consumers may reduce food waste $[2,4,10]$, little is known about how consumers can be made to act on it and what consumers will do with savings on previously wasted food. A forthcoming study by Waste \& Resources Action Programme (WRAP), looking into UK household food consumption behaviour in relation to waste [26], finds that an increase in food waste awareness (through increased media coverage) lowers the amount of food purchased whereas food intake and food sale revenues remain the same. The latter suggests that trading up takes place in that UK households tend to buy smaller quantities of higher priced foods. It contradicts economic theory somewhat in that, ceteris paribus, we would expect food intake to increase and some of the savings on previously wasted food (that was spent on food before) to also be spent on non-food items. Integration of such research into a general equilibrium framework would 
be useful so as to take into account broader food supply chain and economy-wide interactions.

Third, the results of these impact analyses need to be presented in a clear and comprehensive way, stating the assumptions made (regarding the factors incorporated and methods used), and doing justice to the research questions at hand. Two points merit further attention in this respect. These may appear trivial at first sight, but examples are included that aim to illustrate each point.

First, what are the indicators used to measure impacts? Common impact indicators include gross domestic product (GDP), sector production and prices, employment and wages, land use and prices, household income, consumption of foods (diets) and other commodities, and prices paid by households, and trade (exports, imports, trade balance). As shown from the theory, outcomes are likely to vary with the type of indicator used. Hence what may be a desirable outcome from the perspective of one indicator, may not be so from the perspective of another indicator. A clear example is that whilst consumers in industrialised countries may be better off when avoiding waste, some producers may suffer from reduced revenues and incomes, with associated negative employment impacts, to the benefit of producers and employment in other sectors. Trade-offs may extend beyond economic indicators and may also involve environmental and health indicators. For example, whilst reduced food waste may save on land use in food production, trading up on the side of consumers in terms of increased spending on higher priced and more luxurious foods may imply a more unhealthy diet and increased health care costs. With the interest in current literature being focused on broader social impacts (including economic, health and environmental impacts) it is crucial to report the impacts in terms of indicators covering these adequately. It is thus insufficient, , to merely state, as the current literature does, what the impact is likely to be only on consumers if they reduce waste (or equivalently, only on producers if they were reduce losses), without any consideration of broader impacts on society, or for that matter, without any consideration of costs. An interesting research question to look into is to find out whether there is an optimal level of food losses and/or waste taking into account both costs and benefits and to see whether this optimal level differs between private agents and society as a whole. The literature and policy makers currently suggest that food losses and waste are a public bad and should be reduced to zero. Our analyses point out that there may well be an optimum, given that there are costs and trade-offs involved in reducing food losses and/or waste.

Second, what is the benchmark or reference scenario for analysis? If we are interested in the impacts of tackling food losses and waste over time, we need to specify a so-called baseline or business-as-usual scenario to which we can contrast alternative scenarios regarding reductions in food losses and waste. The baseline traditionally assumes a continuation of current trends and no change in policies. Usually this involves capturing current population and economic growth trends, changes in dietary patterns and making assumptions on technological change processes over time. Moreover, almost certain changes in the area of trade, such as the conclusion of multilateral or bilateral free-trade agreements, or domestic policies in the near future may also be incorporated. These trends and policies are likely to affect the outcomes as the impacts on a certain indicator should be presented in difference (absolute, percentage change or change in percentage points) from the outcomes under the baseline so as to isolate the impacts of a particular analysed scenario. An example is that free-trade agreements are very likely to alter the pattern of trade between countries and therefore, the sources of foods supplied and consumed in a country; the EU-US and trans-Pacific trade agreements, which are currently being negotiated, seem particularly relevant here. Baseline construction is by no means straightforward but necessary to come to accurate projections of impacts in the future [27]. It is, therefore, not uncommon to see more than one baseline (for example, baselines with low, medium and high growth; or baselines with or without trade agreements). Developments in the baseline also qualify the results of projections. Taking the example of reduced food waste by households in industrialised countries, the losses to some food producers may appear minor in the light of expected future increases in food sale revenues from increasing demands for food.

\section{Implications for policy}

Policy makers ideally should use the outcomes of applied studies on the economy-wide impacts of reducing food losses and food waste as an input to determine what commodity and what element(s) of the food supply chain to focus on. In an international context, policy makers from the various countries in the world can discuss their respective roles in and contributions to reducing food losses and waste. This is in contrast with what is happening now; following the current literature, the focus of policies is being driven by mere assertions of the size of food waste and losses, not societal impacts (benefits and costs) and ignoring the broader policy context. The consequence of this approach is that policy efforts and resources are currently not being put where they will be most cost-effective from a societal perspective.

Making policy using the outcomes of applied studies is by no means easy. It requires taking into account the trade-offs most likely to come out of any research, weighing and ranking the outcomes of the various indicators according to the priorities of policy makers. 
Naturally, other considerations such as health and environmental aspects play a role, but political and cultural aspects that cannot be modelled or quantified also play a role. Moreover, other avenues of reaching the aforementioned goals should be considered as well. For example, if the prime concern of policy makers in industrialised countries is to improve resource efficiency and reduce environmental impacts, it may well be crucial to encourage consumers to follow a more healthy diet rather than focusing only on food waste reductions. Similarly, if the interest is also to improve food security in developing countries, trade liberalisation and investment policies may be more effective and should then at least also be considered.

Second, policy makers should move beyond formulating targets for reducing food losses and food waste, such as the European Commission's target of reducing food waste by $50 \%$ in 2020 [28], and tackle the underlying causes. Food losses and food waste are nothing new and happen for a reason. Not tackling the root causes is unlikely to yield long-term sustained reductions in food losses and/or waste. With low food prices being cited as a major cause relative to high costs of tackling food losses and waste, this may require increasing the value of and appreciation for food through information campaigns, tax and subsidy policies that reduce incentives to engage in wasteful behaviour, but also financial contributions to improve infrastructure for roads, energy and markets. It may also require setting up institutions and carrying out regulatory reform to facilitate private sector investment in the agricultural sector and food industry.

Finally, policies should take the whole supply chain into consideration. If the focus is only on reducing waste by consumers, which seems to be the approach taken by the European Commission and generally most industrialised countries formulating targets on food waste in demand, the problem may move further up the supply chain to food distributors, processors and farmers, and vice versa, if the focus is on reducing food losses in the early stages of the supply chain, they may move towards the end, such as in retail $[4,19]$.

\section{Implications for practice}

The various supply chain actors in the field could benefit from and use the outcomes of applied research by working on innovative solutions and investing in those areas (that is, commodities, stage of the food supply chain and countries) where they will have the greatest beneficial impact. In turn, they could also feed research and policy makers with information on why food losses and waste are occurring, that is, what the bottlenecks are in tackling food losses and waste, and their relative importance.

Figure 3 summarises the implications for research, policy and practice, naturally with feedback loops as research, policy and practice do not stand on their own, but inform and benefit one another. This facilitates a virtuous circle, of increasing our knowledge on the causes and impacts of food losses and food waste, enabling the fine tuning of policies, and leading to better outcomes for the various actors in the food supply chain.

\section{Conclusions}

This paper, if anything, has shown that the link from reducing food losses and/or waste to food security and welfare for producers and consumers is not as straightforward as the literature seems to suggest using standard economic theory. Many factors are shown to play a role, which should be taken on board by further applied research to investigate broader societal impacts. This would greatly improve the information base for policy making, which is currently being driven by mere considerations of the size of food losses and waste, not their impacts on society, and in turn focuses too much on addressing the size of the problem, thereby often ignoring the underlying causes. It would allow for better targeted policies and resources being devoted to areas where impacts are shown to be most beneficial.

\section{Endnotes}

${ }^{\mathrm{a}}$ Food security is most commonly defined as '... when all people, at all times, have physical, social and economic access to sufficient, safe and nutritious food to meet their dietary needs and food preferences for an active and healthy life' [29].

${ }^{\mathrm{b}}$ The exception is a study on healthy and sustainable diets, which also considers the issue of food waste [21]. Rather than using real data, this study assumes that $15 \%$ less food production is required to meet the same level of nutrition. This is implemented as a $15 \%$ supply chain efficiency increase on a global scale, and so cannot distinguish differential impacts of food loss reductions on the supply side and food waste reductions on the demand side. It finds that agricultural prices fall by about $4 \%$, which increases global food consumption.

${ }^{\mathrm{c}}$ As a basis, any standard microeconomic theory book can be used, such as [30].

${ }^{\mathrm{d}}$ While this paper considers the economic impacts of food losses, the issue of losses, or more broadly, resource inefficiencies, is not only confined to foods but is also applicable elsewhere. This analysis can therefore be extended to other non-food commodities.

${ }^{\mathrm{e}}$ Note, that if one were to mistakenly include the area $B A G F$, the overall welfare loss would amount to $D A G F$, the difference between the two demand curves and above the supply curve, which is analogous to the result of the analysis of loss reductions on the supply side. The analysis on the demand side differs from that on the supply side in that the original demand curve includes 


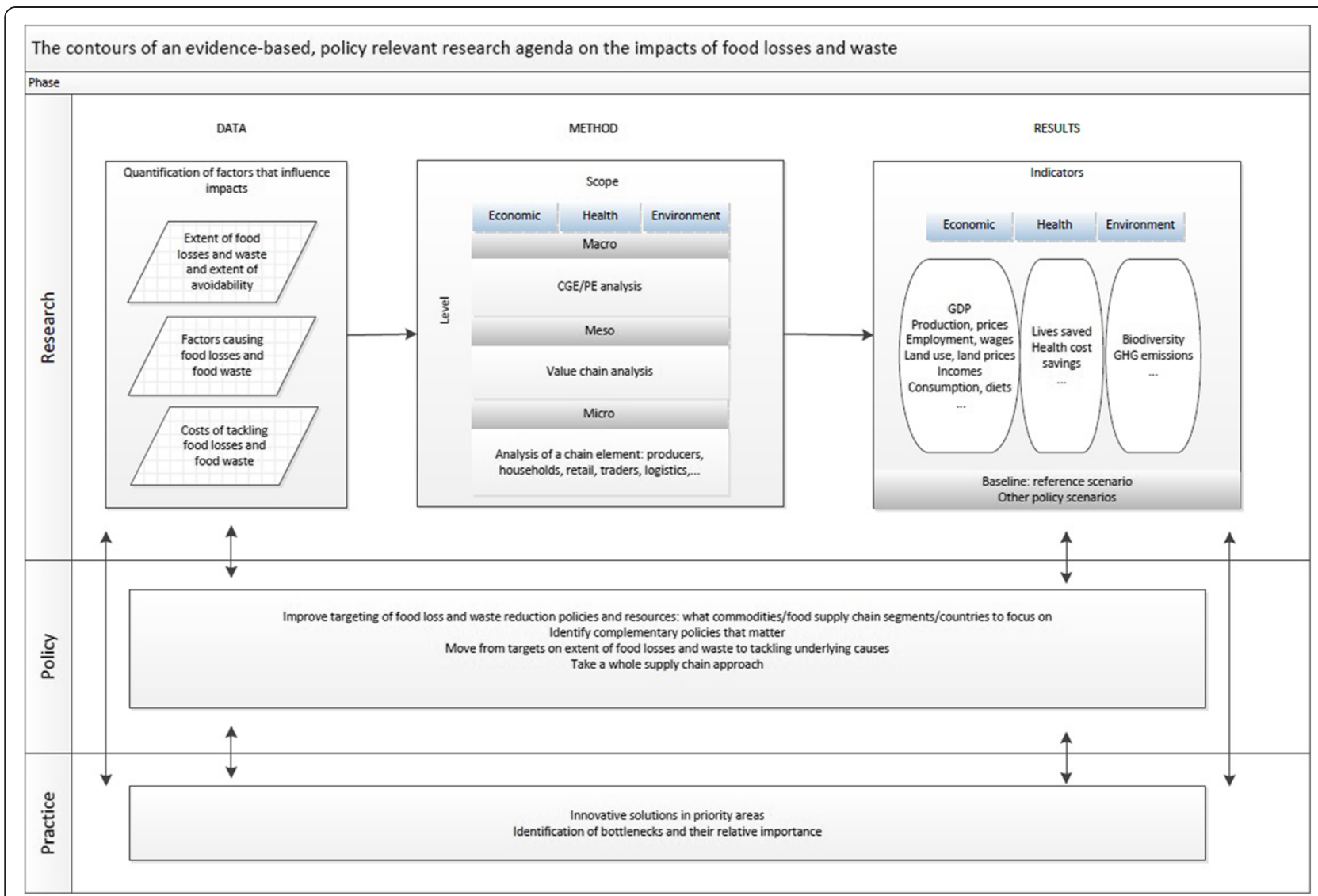

Figure 3 Summary of implications for research, policy and practice. CGE, computable general equilibrium; PE, partial equilibrium; GDP, gross domestic product.

wastage, that is, represents gross demand, whereas the original supply curve is the supply that would result after losses, that is, it represents net supply.

${ }^{\mathrm{f}}$ There is some evidence that consumers may 'trade up' towards more 'luxurious', higher priced foods, such as meats [31]. This further strengthens the outcome of improved food intake of consumers reducing waste in one or more commodity markets. Note, however, that this also potentially brings with it negative health consequences associated with less healthy diets. This is further addressed in the discussion session.

${ }^{\mathrm{g}}$ This is the second notable difference with the analysis of loss reductions on the supply side. Specifically, the loss reduction on the supply side is assumed to benefit the commodity in question in terms of lower costs of producing the same amount of good and/or increased outputs given costs. On the demand side however, it is almost more relevant to know what happens in other markets depending on consumer preferences and following consumer decisions on what to do with the saved expenses on the commodity that previously had wastage.

${ }^{\mathrm{h}}$ Data on food-price elasticities suggest that the demand response for foods can generally be categorised as being inelastic (less than one in absolute value), but estimates generally vary by type of food and may also vary by income level [32]. Specifically for basic food commodities (that is, that form the main staple in a diet) demand will be more inelastic, whereas for more luxurious types of food (for example, soft drinks, meats and foods away from home) demand will be more elastic. Moreover, low-income populations may be more sensitive to price changes. To find price elasticities of demand for specific food commodities and specific countries one can consult an online database provided by the United States Department of Agriculture (USDA) Economic Research Service [33].

${ }^{\mathrm{i}}$ Evidence on supply elasticities for agricultural commodities is mixed but the literature $[34,35]$ suggests that the supply response in the short run is relatively inelastic (elasticity of less than one and more often than not close to zero) and in the long run more elastic (elasticity range from below one to over one), though not perfectly so.

\section{Abbreviations}

CGE: Computable general equilibrium; FAO: Food and Agriculture Organization; FUSIONS: Food Use for Social Innovation by Optimising Waste Prevention Strategies; GDP: Gross domestic product; OECD: Organization for 
Economic Cooperation and Development; PE: partial equilibrium; USDA: United States Department of Agriculture; WRAP: Waste \& Resources Action Programme.

\section{Competing interests}

The author declares that she has no competing interests.

\section{Authors' contributions}

$\mathrm{MR}$ is solely responsible for the manuscript and underlying research.

\section{Authors' information}

$M R$ is researcher at the international policy department of LEI Wageningen $U R$, a leading economic research institute in the fields of food, agriculture and the natural environment in the Netherlands. MR has extensive research experience in the areas of food security, agricultural markets and international trade. She held previous positions as policy advisor in the area of international (financial) economics and as health economics and finance advisor in the context of developing countries.

\section{Acknowledgements}

The author is very grateful to Jeff Powell, Geert Woltjer, Lusiné Amaryan, Peter Nowicki, Yuca Waarts, Gerdien Meijerink, Siemen van Berkum, Adrian Tan, Francois Cohen and Clementine O'Connor for their useful comments and advice. The paper also greatly benefited from comments and suggestions by various participants of the $16^{\text {th }}$ Annual GTAP conference in Shanghai (12 to 14 June, 2013), a discussion session with policy makers at the Dutch Ministry of Economic Affairs (20 June, 2013) and the $4^{\text {th }}$ OECD Food Chain Analysis Network Meeting (20 to 21 June, 2013).

Received: 6 May 2013 Accepted: 12 September 2013

Published: 24 September 2013

\section{References}

1. FAO: How to Feed the World in 2050. Rome: FAO; 2009.

2. FAO: Global Food Losses and Food Waste: Extent, Causes and Prevention. Rome: FAO; 2011.

3. Parfitt J, Barthel M, MacNaughton S: Food waste within food supply chains: quantification and potential for change to 2050. Phil. Trans R Soc B 2011, 365:3065-3081.

4. Lipinski B, Hanson C, Lomax J, Waite R, Searchinger T: Reducing Food Losses and Waste. Working Paper, Installment 2 of Creating a Sustainable Future. Washington DC: World Resources Institute; 2013.

5. FAO: Towards the Future We Want: End Hunger and Make the Transition to Sustainable Agricultural and Food systems. Rome: FAO; 2012.

6. UNEP: Avoiding Future Famines: Strengthening the Ecological Foundation of Food Security through Sustainable Food Systems. Nairobi: UNEP; 2012.

7. UNEP: The Critical Role of Global Food Consumption Patterns in Achieving Sustainable Food Systems and Food for All. Paris: UNEP; 2012.

8. Guyomard H, Darcy-Vrillon B, Esnouf C, Marin M, Russel M, Guillou M: Eating patterns and food systems: critical knowledge requirements for policy design and implementation. Agric Food Secur 2012, 1:13

9. EU FUSIONS. http://www.eu-fusions.org/what-is-fusions.

10. Barilla Center for Food \& Nutrition (BCFN): Food Waste: Causes, Impacts and Proposals. Parma: BCFN; 2012

11. Lundqvist J, de Fraiture C, Molden D: Saving Water: From Field to Fork Curbing Losses and Wastage in the Food Chain. Stockholm: Stockholm International Water Institute (SIWI); 2008.

12. Rutten M, Kavallari A: Can Reductions in Agricultural Food Losses Avoid Some of the Trade-Offs Involved when Safeguarding Domestic Food Security? A Case Study of the Middle East and North Africa. GTAP Resource 4075. https://www.gtap.agecon.purdue.edu/resources/res_display. asp?RecordID $=4075$.

13. Rutten M, Nowicki P, Bogaardt M-J, Aramyan L: Reducing Food Waste by Households and in Retail in the EU: A Prioritisation Using Economic, Land Use and Food Security Impacts. The Hague: LEI Wageningen UR; 2013. unpublished.

14. Waste \& Resources Action Programme (WRAP: The Food We Waste. Banbury: WRAP; 2008

15. Personal communications with Yuca Waarts.

16. Pimentel D, Pimentel M: Sustainability of meat-based and plant-based diets and the environment. Am J Clin Nutr 2003, 78:660S-663S
17. Hoekstra A: The hidden water resource use behind meat and dairy. Animal Frontiers 2012, 2:3-8.

18. OECD Food Chain Network: $4^{\text {th }}$ network meeting 20-21 June 2013. http://www.oecd.org/site/agrfen/.

19. BIO Intelligence Service: Modelling of Milestones for Achieving Resource Efficiency, Turning Milestones into Quantified Objectives: Food Waste. Prepared for the European Commission, DG Environment; unpublished.

20. Okawa K: Agricultural Trade and Markets, OECD: Modelling Work on Food Waste. Presentation at the 4th network meeting of the OECD Food Chain Network: 20-21 June 2013. http://www.oecd.org/site/agrfen/.

21. Westhoek H, Rood T, van den Berg M, Janse J, Nijdam D, Reudink M, Stehfest E: The Protein Puzzle: The Consumption and Production of Meat Dairy and Fish in the European Union. The Hague: Netherlands Environmental Assessment Agency (PBL); 2011

22. Lock K, Smith R, Dangour A, Keogh-Brown M, Pigatto C, Hawkes R, Fisberg C, Chalabi Z: Health, agricultural, and economic effects of adoption of healthy diet recommendations. Lancet 2010, 376:1699-1709.

23. Bussolo M, de Hoyos R, Medvedev D: Economic growth and income distribution: linking macro economic models with household survey data at the global level. Int J Microsimulation 2010, 3:92-102.

24. Hertel T, Verma M, Ivanic M, Rios A: GTAP-POV: A Framework for Assessing the National Poverty Impacts of Global Economic and Environmental Policies. GTAP Technical Paper 31. 2011. https://www.gtap.agecon.purdue. edu/resources/res display.asp?RecordID=3731.

25. Bouet A, Estrades C, Laborde D: Households Heterogeneity in a Global CGE Model: An Illustration with the MIRAGE Poverty Module. GTAP Resource 3631. 2011. https://www.gtap.agecon.purdue.edu/resources/ res display.asp?RecordID $=3631$

26. WRAP: The Economics of Food Waste. Prepared by Fathom Financial Consulting; in press.

27. Dixon P, Rimmer M: Forecasting with a CGE Model: Does it Work. Centre of Policy Studies and the Impact Project, General Paper No. G-197. 2009.

28. Commission E: Roadmap to a Resource Efficient Europe. COM(2011) 571 final. Brussels: European Commission; 2011

29. FAO: Rome Declaration on World Food Security and World Food Summit Plan of Action. Rome: World Food Summit; 1996.

30. Jehle A, Reny P: Advanced Microeconomic Theory. New York: AddisonWesley; 1998.

31. Government Office for Science: Foresight Project on Global Food and Farming Futures. Synthesis Report C7: Reducing waste. London: Government Office for Science; 2011.

32. Andreyeva $T$, Long M, Brownell $K$ : The impact of food prices on consumption: a systematic review of research on the price elasticity of demand for food. Am J Public Health 2010, 100:216-219.

33. USDA Economic Research Service Commodity and Food Elasticities. http:// www.ers.usda.gov/data-products/commodity-and-food-elasticities.aspx.

34. Nerlove M, Addison W: Statistical estimation of long-run elasticities of supply and demand. J Farm Econ 1958, 40:861-880

35. Rao J: Agricultural supply response: a survey. Agric Econ 1989, 3:1-22.

\section{doi:10.1186/2048-7010-2-13}

Cite this article as: Rutten: What economic theory tells us about the impacts of reducing food losses and/or waste: implications for research, policy and practice. Agriculture \& Food Security 2013 2:13

\section{Submit your next manuscript to BioMed Central and take full advantage of:}

- Convenient online submission

- Thorough peer review

- No space constraints or color figure charges

- Immediate publication on acceptance

- Inclusion in PubMed, CAS, Scopus and Google Scholar

- Research which is freely available for redistribution 